\title{
El futuro del pasado
}

The future of the past

\section{Resumen:}

Autor:

Arq. Mst. Nancy Quezada Dumas

\section{Directora de Áreas Históricas y Patrimoniales}

GAD Municipal de Cuenca

(Ecuador)

Recibido: 20 de Noviembre 2014 Aceptado: 20 de Diciembre 2014 


\section{Introducción}

Debemos partir de la pregunta fundamental ¿por qué preservamos el patrimonio? o ¿por qué es importante preservar el patrimonio edificado? Obviamente tenemos una obligación internacional para conservar nuestro legado por la declaratoria de Cuenca Patrimonio Cultural de la Humanidad hace 15 años. Las fechas emblemáticas como la de esta declaratoria, también nos deben llevar a reflexionar sobre la misma esencia o razón por la que estamos haciendo todos estos esfuerzos. $Y$ sabemos las respuestas, pero a veces es necesario repetirlas: la conservación del patrimonio es importante porque tiene que ver con lo que somos y con lo que vamos a ser. El patrimonio edificado es el escenario de nuestras vidas, de las vidas de nuestros abuelos y de nuestros nietos. En la indagación y experiencia de estos espacios se entretejen las historias y costumbres que nos hacen lo que somos, y somos cuencanos, orgullosos de nuestro legado, que además, lo seguimos viviendo.

\section{Resultados del trabajo de conservación}

Una vez establecida la razón de ser del patrimonio, debemos reflexionar sobre el trabajo realizado durante los últimos 15 años para su preservación y convivencia con el presente. Como en todo proceso, porque esto es un proceso constante de trabajo continuo, podemos afirmar que hemos alcanzado grandes e importantes aciertos, pero lamentablemente tenemos que reconocer que también hemos cometido errores que tenemos que corregir. (Ver Imagen 1).

Uno de los aciertos importantes fue la actualización de la Ordenanza para la Gestión y Conservación de las Áreas Históricas y Patrimoniales del Cantón Cuenca expedida en febrero de 2010, que en la actualidad nos permite trabajar con una normativa actualizada. También fue un acierto ampliar los límites de las Áreas Históricas y Patrimoniales, lo que nos dio una herramienta para preservar también importantes inmuebles fuera del núcleo más antiguo del centro urbano; extender nuestra visión de lo patrimonial al pasado inmediato anterior, y aumentar el número de edificaciones a preservar.

Sin embargo, fue un error de este proceso no articular la información de los inventarios que precedieron al último, que se elaboró en el 2009. No obstante, es importante aclarar que actualmente estamos superando esta falencia. Un grupo de profesionales en la Dirección de Áreas Históricas y Patrimoniales están documentando esta información valiosa con la finalidad de contar con una base de datos que permita tener el historial completo de cada predio desde mediados de la década de los setenta.

\section{Bondades y limitaciones del esquema de gestión vigente}

Los organizadores del «Seminario de actores locales por los 15 años de inclusión de Cuenca en la lista del Patrimonio Mundial», también nos han pedido referirnos a las bondades y limitaciones del esquema de gestión vigente en relación a la preservación del patrimonio que incluye a la Dirección a mi cargo como entidad técnica de control, gestión y planificación, en trabajo conjunto con la Fundación el Barranco.

Podemos encontrar este esquema limitado y con falencias administrativas, sin embargo, uno de los grandes vacíos que se han detectado ha sido el brazo que pueda fortalecer nuestro conocimiento sobre el patrimonio para poder difundirlo a la ciudadanía y generar una conciencia colectiva sobre la importancia de la conservación.

En atención a lo expuesto, se ha activado una unidad de investigación y difusión dentro de la Dirección de Áreas Históricas y Patrimoniales, una rama que debe conectarse con los demás actores del esquema de gestión, que no solo incluye el GAD Municipal sino a las universidades, entidades públicas y privadas, y al ciudadano en general. (Ver Imagen 2).

La articulación de los demás actores es indispensable para lograr la preservación 


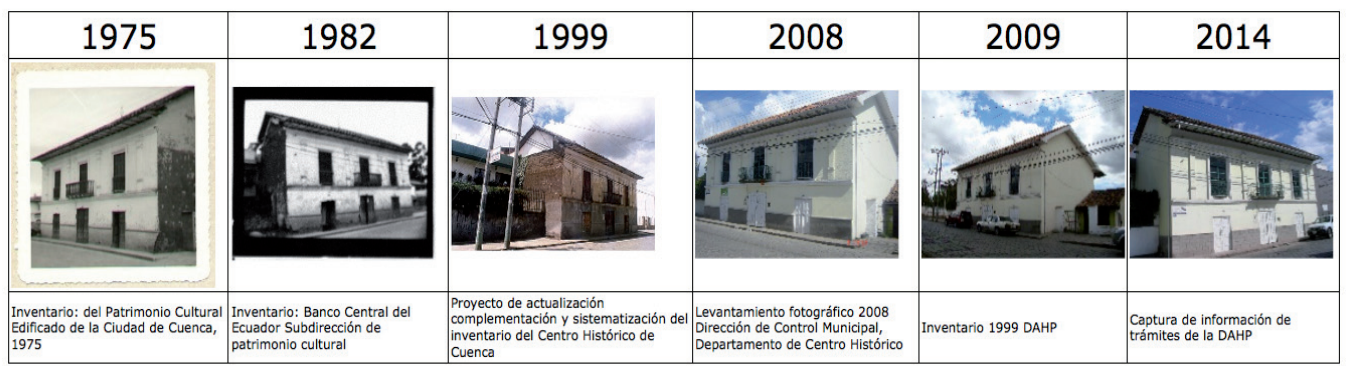

Imagen 1. Sistema de documentación del patrimonio edificado de las Áreas Históricas y Patrimoniales. Vivienda de la Av. Loja 2-194 .

Fuente: Propia

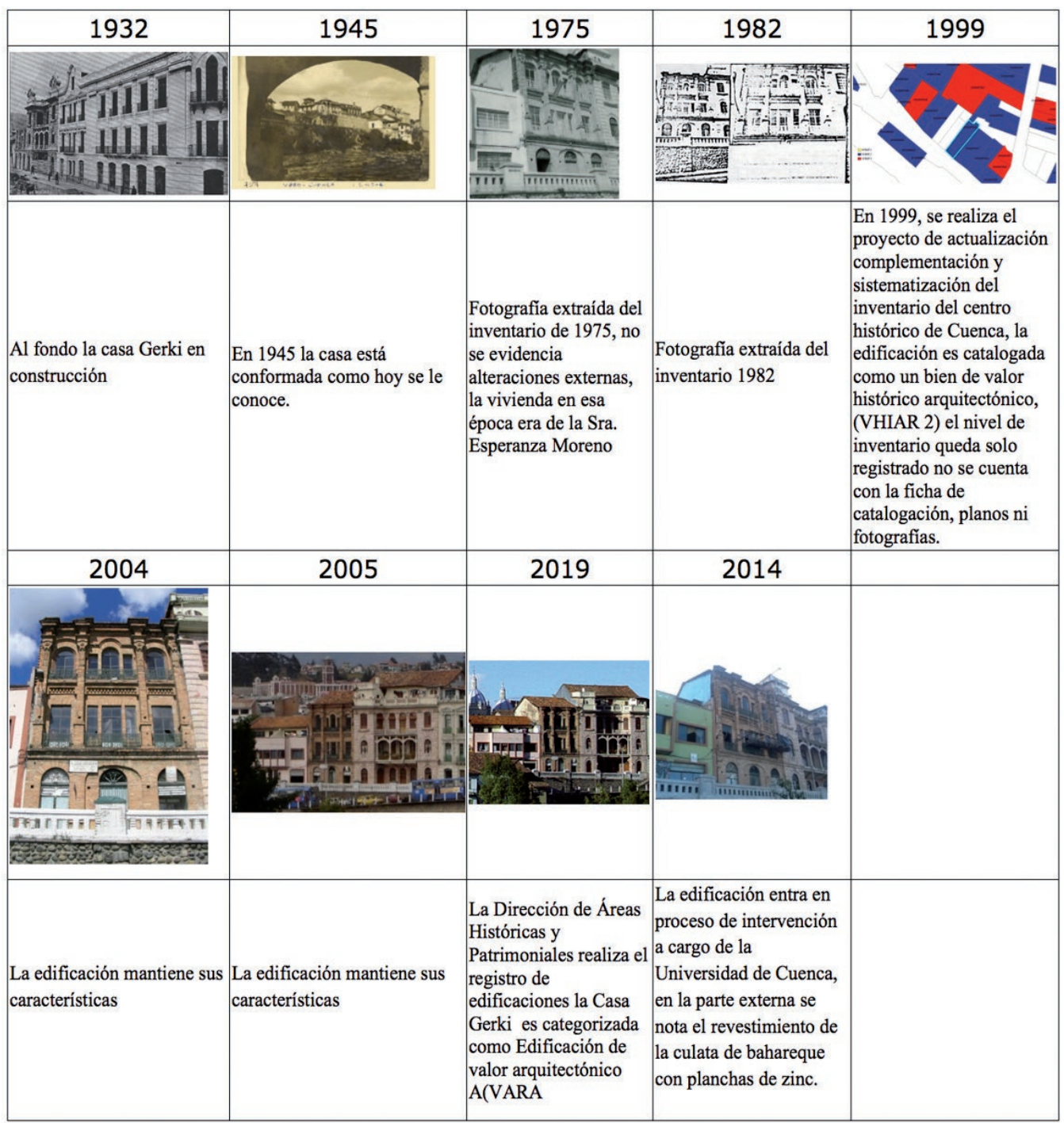

Imagen 2.Sistema de documentación del patrimonio edificado de las Áreas Históricas y Patrimoniales. Casa Gerki, Calle La Condamine 12-70.

Fuente: Propia 


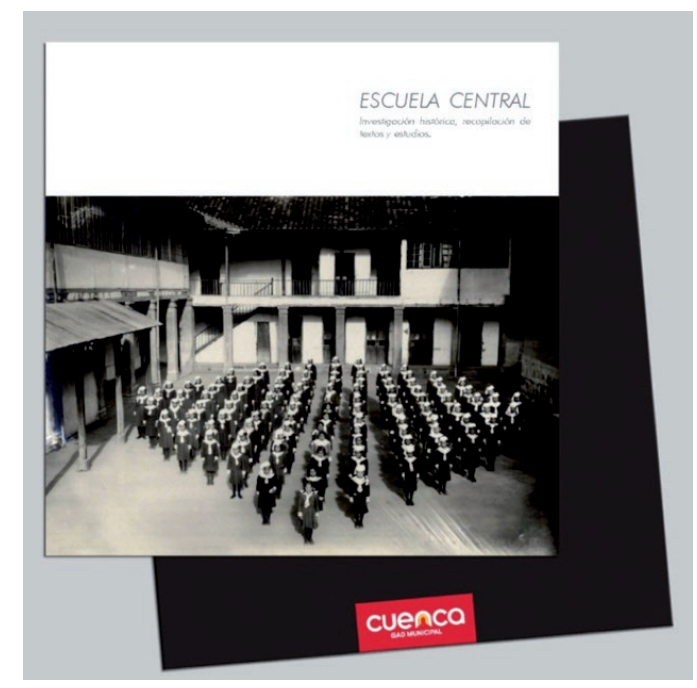

Imagen 3. Portada de libro publicado por la Dirección de Áreas Históricas y Patrimoniales en 2014 con el objetivo de difundir información en torno al inmueble patrimonial conocido como Escuela Central.

Fuente: Propia

\begin{tabular}{|lc|}
\hline $\begin{array}{l}\text { Inmuebles catalogados } \\
\text { con categoría Emergente: }\end{array}$ & 43 \\
\hline $\begin{array}{l}\text { Inmuebles catalogados } \\
\text { con categoría VAR A (3): }\end{array}$ & 204 \\
\hline $\begin{array}{l}\text { Inmuebles catalogados } \\
\text { con categoría VAR B (2): }\end{array}$ & 1548 \\
\hline $\begin{array}{l}\text { Inmuebles catalogados } \\
\text { con categoría Ambiental (1): }\end{array}$ & 1492 \\
\hline Total del inventario: & 3287 \\
\hline
\end{tabular}

Gráfico1. Número de edificaciones patrimoniales (inventario efectuado en el año 2009), de acuerdo a la categoría de valor, que tenemos actualmente.

Fuente: Propia del patrimonio y asegurar el futuro de nuestro legado; si no logramos generar una conciencia en el individuo, el propietario del inmueble, el usuario, el arrendatario y el arquitecto, no vamos a lograr como ciudad, anteponer la preservación del patrimonio a los intereses económicos que impulsan hacia una explotación cada vez mayor del suelo y que imponen edificaciones de mayor altura y rentabilidad económica; mayores concesiones, e intervenciones para el beneficio de los diversos negocios. En esta parte tiene fundamental importancia el apoyo de las universidades, que también son generadoras de nuevos conocimientos que seguirán fortaleciendo este proceso, como lo han venido haciendo a lo largo de los años. (Ver Imagen 3).

\section{Inventarios de edificaciones y espacios públicos del Centro Histórico de Cuenca}

Uno de estos enlaces, que generó fruto en su debido momento, fue precisamente la actualización del inventario de edificaciones y espacios públicos del Centro Histórico de Cuenca basado en un estudio realizado por el Proyecto VLIR-IUC en el 2009.

Fueron tres los inventarios que antecedieron a éste último: el de 1975, que fue un primer inventario del patrimonio arquitectónico elaborado por el Instituto de Patrimonio Artístico de la Casa de la Cultura Núcleo del Azuay y dirigido por el arquitecto Patricio Muñoz. En total se registraron 1018 edificaciones en aquel momento.

Un segundo inventario se elaboró en 1982 como parte fundamental para la declaratoria de Cuenca como Patrimonio de la Nación. A diferencia del primer trabajo, éste inventario especificó las edificaciones a conservar en función de diversos parámetros: el grado de conservación, características estéticas formales, estado de la construcción, relación con el entorno, grado de edificabilidad y usos (Jaramillo, 2008). Otra innovación fue la sectorización del Centro Histórico que se dividió en tres zonas: Área de primer orden, Área de respeto y Áreas especiales. También se generó una Ordenanza para el control y la administración del Centro Histórico. 
Posteriormente, con el fin de fortalecer la candidatura de Cuenca como Patrimonio Cultural de la Humanidad, la Municipalidad de Cuenca inició en 1997 el proyecto denominado «Catastro Monumental Urbano: actualización, complementación y sistematización del inventario de edificaciones patrimoniales del Centro Histórico de Cuenca». El resultado del proyecto fue el registro de 2040 edificaciones patrimoniales del Centro Histórico. Este trabajo ya difiere de los anteriores por la calidad de los levantamientos arquitectónicos y los levantamientos fotográficos detallados a través de los sistemas de informática que ya estaban disponibles en aquel momento. También se realizó una identificación minuciosa de los usos que se daba a cada inmueble, descripciones arquitectónicas y recomendaciones de mantenimiento.

En aquella ocasión se trabajó con categorías de valoración que contemplaban el valor histórico y arquitectónico de las edificaciones: los VHIAR de primer, segundo y tercer orden.

El recuento de los inventarios realizados nos lleva a la conclusión de que han sido un elemento esencial en el trabajo de conservación de las últimas décadas. Sin ellos, no se hubiera tenido conocimiento sobrelosbienesa preservar.Además, como mencioné antes, en la actualidad son una piedra angular para el trabajo de documentación que se está ejecutando. Sin embargo, tenemos que constatar lamentablemente, que en algunos casos no se han respetado los inventarios, en un primer momento, por la falta de un marco legal que pudiera obligar a la conservación. (Ver Gráfico 1).

Por otro lado, se evidencia que los inventarios se han elaborado como proyectos puntuales con intervalos de más o menos una década. Tenemos claro que el inventario debe ser un proceso continuo dentro de un sistema de actualización en función de las intervenciones que se hacen en el Centro Histórico (aproximadamente 120 por año). En este sentido, es muy importante tomar en cuenta que un inmueble que anteriormente no fue calificado como patrimonial, en la actualidad, con nuevos conocimientos adquiridos, puede ser revalorado. Esta información reciente debe sumarse a la documentación de los inventarios anteriores de manera que se genere una base completa que revele el estado de cada uno de los inmuebles a través del tiempo. (Ver imagen 4).

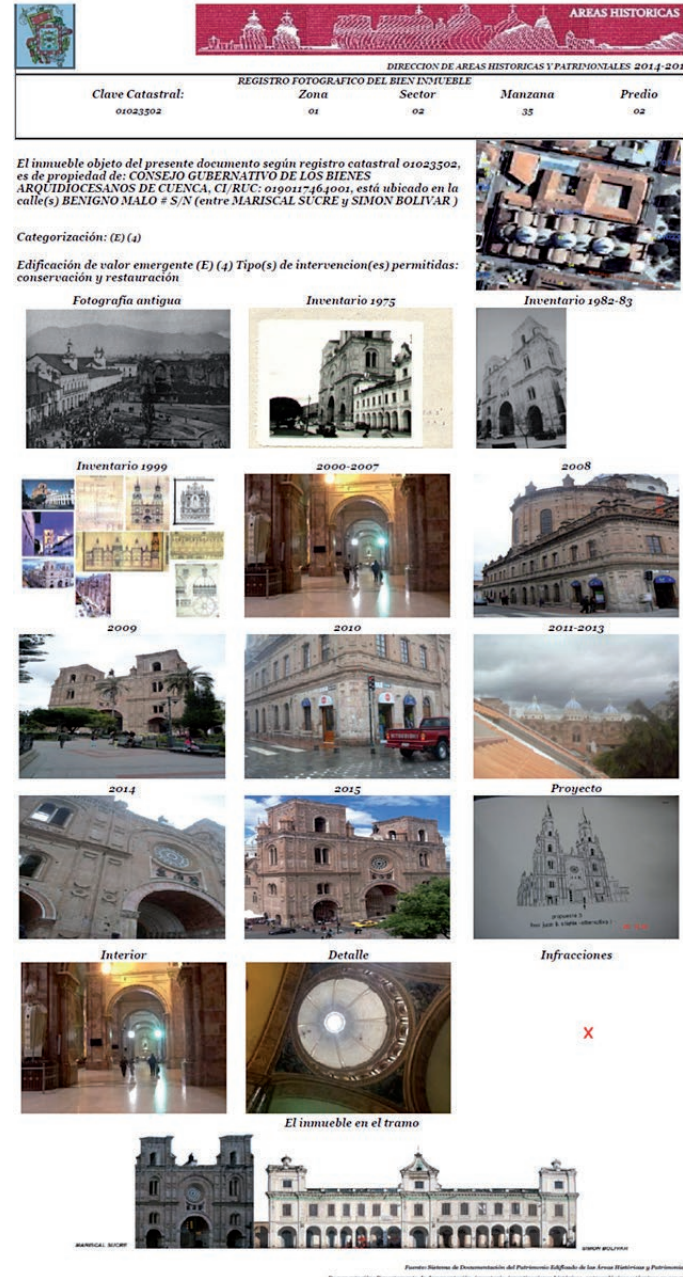

Imagen 4. Portada de libro publicado por la Dirección de Áreas Históricas y Patrimoniales en 2014 con el objetivo de difundir información en torno al inmueble patrimonial conocido como Escuela Central.

Fuente: Propia 
Este trabajo que se está realizando actualmente, se conectará con un proceso de investigación y sistematización histórica que se ha emprendido con la finalidad de conocer el origen y el estado del patrimonio antes de la elaboración los inventarios, de manera que en el futuro podamos contar con una gran base de datos que revele extensamente el historial de los bienes inmuebles y los espacios públicos. Creemos firmemente que con esta ampliación y sistematización de nuestro conocimiento sobre el patrimonio y la utilización de medios que permitan difundir ampliamente la información adquirida, vamos a estar mejor preparados para contrarrestar las fuerzas que priorizan otros aspectos sobre la preservación, desde las instituciones que formalmente están a cargo de la tarea de la conservación hasta el ciudadano en general. Entendemos que lo que no se conoce tampoco se valora debidamente, de manera que una concientización generalizada es indispensable.

Por otro lado, se ha detectado un cambio en la valoración de los inmuebles. Este aspecto debe ser revisado y analizado tomando en cuenta que el valor global de cada edificación patrimonial se origina en otros valores, no solo en el arquitectónico o estético, sino en el histórico, tecnológico, de uso y social. Este último está además íntimamente ligado al patrimonio inmaterial, a nuestras tradiciones y costumbres, a la vida diaria y a los días festivos de quienes vivimos en esta ciudad.

\section{Relación entre el patrimonio material y el patrimonio inmaterial}

Todavía podemos decir que el patrimonio material y el inmaterial comparten el espacio. Las áreas históricas y patrimoniales de nuestra ciudad son el escenario de actos y costumbres heredados del pasado como El Pase del Niño, el Corpus Cristi, la Fiestas del Santísimo, la Visita a las 7 Iglesias en la Semana Mayor y muchos otros, así como de las actividades más cotidianas que reflejan nuestro legado como el fotografiarse en el Parque Calderón, la venta de paja para la elaboración de los sombreros, la asistencia a cultos religiosos, la comercialización de productos artesanales, entre muchas más que están en la categoría de patrimonio intangible.

No obstante, se tiene que admitir que no se ha priorizado el trabajo para la conservación del patrimonio inmaterial en la manera debida. Sin embargo, con satisfacción podemos decir que dentro de la Unidad de investigación de la Dirección de áreas Históricas y Patrimoniales, a la que ya nos referimos anteriormente, esta parte del legado patrimonial está tomada en cuenta. Aunque este trabajo inició anteriormente, deseamos reforzarlo en el futuro, para que podamos fortalecer las conexiones y espacios compartidos del patrimonio en una ciudad activa y contemporánea con su identidad bien fundamentada en el legado patrimonial y en las diversas manifestaciones del patrimonio intangible, y con una conciencia colectiva y generalizada de preservación y conservación.

\section{Conclusión}

Los 15 años transcurridos desde la declaratoria de Cuenca como Patrimonio Cultural de la Humanidad nos llama a la reflexión sobre el estado actual y el futuro de nuestro legado. Podemos afirmar que hemos visto desplegado un gran trabajo para la conservación del patrimonio edificado, sin embargo nos falta fortalecer los lazos entre los diversos actores - tanto públicos como privados - vinculados al trabajo de preservación. Es indispensable ampliar nuestro conocimiento sobre el patrimonio y lograr su difusión masiva con el objetivo de que el ciudadano común adopte una nueva visión y busque ser partícipe de ésta tarea que solo se logrará con un esfuerzo colectivo. Es necesario que cada arquitecto que va a intervenir en el patrimonio, cada propietario y cada habitante comparta los valores fundamentales que nos llevan a la conservación de los inmuebles patrimoniales y a la revalorización del patrimonio intangible. 


\section{Bibliografía}

- ASTUDILLO, S., y JARAMILLO, D. 2008. "Análisis de los Inventarios de Patrimonio Cultural en la Ciudad de Cuenca". In 50 Años de la Facultad de Arquitectura de la Universidad de Cuenca, edited by $C$. Jaramillo, 24 - 32, Cuenca: Grafisum.

- Ilustre Municipio de Cuenca; Sistema de Documentación del patrimonio edificado de las Aéreas Históricas y Patrimoniales.

- Ilustre Municipio de Cuenca, Dirección de Áreas Históricas y Patrimoniales, Investigación histórica, recopilación de textos y estudios, 2014 